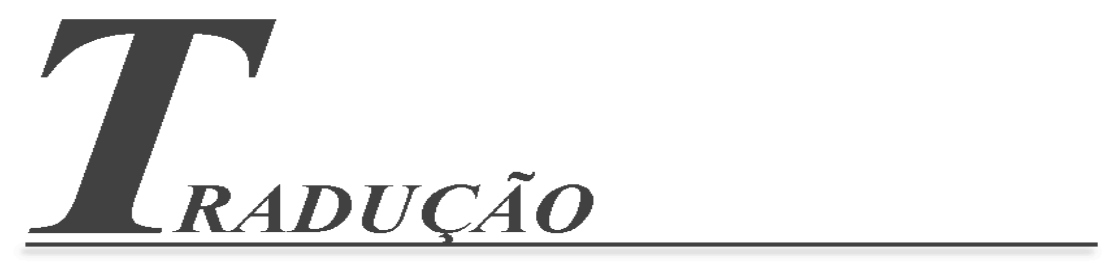

\title{
O Direito Humano à Participação Política ${ }^{1}$
}

\author{
Fabienne Peter \\ Traduzido por Vitor Luiz Rigoti dos Anjos ${ }^{* *}$ \\ recebido: $02 / 2014$ \\ aprovado: $06 / 2014$
}

\section{Introdução}

A crescente importância dos direitos humanos após a Segunda Guerra Mundial pôs um fim na doutrina de soberania do Estado como a principal norma política no âmbito global. Os direitos humanos se tornaram o centro de uma pauta distintivamente política e legal para a ordem global animada por valores igualitários. Os direitos humanos impõem padrões fixos mínimos tanto nas instituições políticas e no ordenamento legal nacional quanto nas relações internacionais e nas instituições globais.

Na medida em que os direitos humanos têm, nesta forma, se tornado parte das exigências da legitimidade política, surge a questão de quão extensa a lista de direitos humanos deveria ser. No recente debate em filosofia, tem havido uma tendência a

\footnotetext{
* Professora associada do Departamento de Filosofia da Universidade de Warwick, especializada nas áreas de Filosofia Política, Filosofia Moral e Epistemologia Social. Seu perfil e currículo estão disponiveis na página http://www2.warwick.ac.uk/fac/soc/philosophy/people/faculty/peter/ Acessoem:12nov.2013.Em@il:f.peter@warwick.ac.uk ** Licenciado em Filosofia pela Faculdade Padre João Bagozzi, em Curitiba/PR. Mestre em Engenharia Mecânica pela UFES. Em@il:vitorlranjos@yahoo.com.br
} 
resistir às tendências inflacionárias na identificação do que conta como um direito humano e a endossar listas minimalistas de direitos humanos. $O$ direito à participação política, em particular, embora destacado nos tratados originais de direitos humanos e na prática contemporânea de direitos humanos, muitas vezes não consegue obter apoio ou é até mesmo explicitamente excluído. Contra estes pontos de vista, quero defender a alegação de que um direito de participação política deve ter lugar mesmo nas listas minimalistas de direitos humanos.

Meu argumento tem como objetivo mostrar que os direitos humanos deixarão de garantir legitimidade política se o direito à participação política for excluído do conjunto de direitos básicos. Isso depende de uma distinção entre dois problemas de legitimidade que surgem com os direitos humanos. O primeiro, que podemos chamar de problema dos padrões, diz respeito à exigência de que as instituições e as decisões políticas - em níveis nacional, internacional e global - se aplicam e satisfazem a um padrão de direitos humanos. Uma vez que um padrão de direitos humanos não é o único requisito de legitimidade, o primeiro problema diz respeito à relação entre um padrão de direitos humanos e outras fontes de legitimidade política. No contexto de um Estado democrático, por exemplo, o problema dos padrões dá origem à questão de como um conceito de legitimidade democrática pode acomodar tanto um padrão de direitos humanos quanto um princípio de autodeterminação democrática. No contexto do reconhecimento internacional dos Estados, para dar outro exemplo, o problema manifesta-se na questão de como equilibrar o respeito aos direitos humanos com as restrições sobre as intervenções de terceiros. Este problema dos padrões é uma razão para favorecer as listas minimalistas de direitos humanos.

O segundo problema da legitimidade, que é muitas vezes obscurecido, diz respeito à justificação de um padrão próprio de direitos humanos. Argumentarei que, devido a este problema da justificação, um direito humano à participação política é necessário - embora não suficiente - para a legitimidade política e deve figurar até mesmo em listas minimalistas de direitos humanos. 
Terminarei o artigo com uma discussão sobre em que consiste um direito de participação política. O debate atual se centra em saber se há ou não um direito à democracia (por exemplo, Christiano, 2011a). Argumentarei que o direito à participação política não precisa ser interpretado como um direito à democracia, e defenderei uma exigência mais fraca do que o direito à democracia. Em outro aspecto, no entanto, meu argumento tem uma implicação exigente. $\mathrm{Na}$ prática contemporânea dos direitos humanos, o direito à participação política é enquadrado como um direito de participar nos assuntos políticos nacionais. Meu argumento em defesa do direito à participação política implica que o direito deve ser expandido para incluir também a participação no debate político global, e eu discutirei brevemente este assunto.

Em suma, meu artigo defende as seguintes afirmações centrais: (i) os direitos humanos são mais bem compreendidos em termos da sua conexão com a legitimidade política; (ii) a legitimidade política requer não apenas que um padrão de direitos humanos seja aplicado e satisfeito, mas também que o próprio padrão seja justificado de modo correto; e (iii) um direito à participação política, devidamente compreendido, é necessário, mas não suficiente, para a legitimidade política.Arte é a apresentação da Ideia em sua forma sensorial.

\section{Direitos Humanos}

Antes que eu possa chegar à parte principal do meu argumento, preciso dizer algo sobre direitos humanos em geral. A ideia de direitos humanos tem, naturalmente, uma longa história na tradição dos direitos naturais. Entretanto, os desenvolvimentos recentes têm inspirado muitos a argumentar que a concepção tradicional de direitos humanos - definidos como direitos que as pessoas têm "simplesmente em virtude de sua humanidade" (Simmons, 2001, p. 185) - deveria ser substituída por uma concepção política. John Tasioulas (2009) prestativamente identifica duas dimensões principais da discordância no debate atual sobre as concepções de direitos humanos. A primeira discordância é sobre o que os direitos humanos são, e a segunda sobre como eles são justificados. De 
acordo com a concepção tradicional, os direitos humanos são direitos morais que as pessoas têm como características marcantes de sua humanidade. Estas características podem estar relacionadas com as necessidades ou os interesses fundamentais (por exemplo, Miller, 2012) ou com os aspectos básicos da ação humana (por exemplo, Griffin, 2008) ${ }^{2}$. De acordo com a concepção política, pelo contrário, os direitos humanos são um conjunto de direitos especiais que têm suas origens em características marcantes da prática contemporânea de direitos humanos (por exemplo, Rawls, 1999; Beitz, 2009). Assim como as concepções tradicionais, as concepções políticas diferem-se em relação às características marcantes relevantes. Um exemplo proeminente é o foco de John Rawls sobre as intervenções de terceiros (Rawls, 1999) ${ }^{3}$. Outros defensores de uma concepção política tendem a dar caracterizações mais amplas da prática contemporânea de direitos humanos (por exemplo, Beitz, 2009).

A respeito da questão sobre o que justifica os direitos humanos, os defensores da concepção tradicional geralmente sustentam que o raciocínio moral comum é necessário e suficiente para estabelecer o que deve contar como um direito humano. Os defensores da concepção política, por outro lado, geralmente sustentam que os direitos humanos são justificados por algum tipo de razão pública ou de raciocínio público. Os direitos humanos, por esse ponto de vista, não são descobertos e sim construídos em um processo devidamente limitado de deliberação prática. Discutirei essa dimensão do debate com mais detalhes um pouco mais abaixo nesta seção.

Note-se que, juntamente com estas formas puras das concepções tradicional e política de direitos humanos, alguns autores têm recentemente proposto concepções mistas. Eu penso que Joseph Raz $(2007,2010)$ seja mais bem entendido como defensor de uma concepção mista. Ele aceita a concepção política a respeito da primeira dimensão - a questão sobre o que os direitos humanos são - mas ele combina isso com a visão de que o que justifica os direitos humanos é um raciocínio moral comum. Rainer Forst (2010) pende à direção oposta: ele define os direitos humanos com base nas características marcantes da ação humana, mas responde à pergunta de como eles são justificados ao invocar uma ideia de raciocínio público ${ }^{4}$. 
Minhas simpatias estão com a forma pura da concepção política de direitos humanos. Sou incapaz de aqui discutir o caso, mas quero listar algumas considerações em favor da concepção política ${ }^{5}$. Em primeiro lugar, não é preciso negar a tese histórica sobre direitos humanos - que surgiu a partir da tradição dos direitos naturais -, a fim de sustentar que os direitos humanos foram relançados em 1948 como um projeto especificamente político-legal. Aqui sigo Charles Beitz (2009), que argumenta que a tese histórica não implica uma tese filosófica sobre o que os direitos humanos são e sobre o que explica a autoridade que eles têm hoje. Pode-se, assim, tanto a aceitar a tese histórica e sustentar que a melhor compreensão dos direitos humanos hoje é aquela que rompe com a noção de que os direitos humanos são direitos morais que todos os indivíduos têm em virtude de sua humanidade.

Uma segunda consideração está imediatamente relacionada. Independentemente dos méritos de interpretar os direitos humanos à luz da tradição dos direitos naturais, fazer isso é insuficiente para captar as características distintivas da prática contemporânea de direitos humanos. A prática contemporânea identifica direitos humanos com um conjunto de normas explicitamente políticas que só fazem sentido em determinados contextos institucionais (Nickel, 2007). Os direitos humanos obtêm seu conteúdo distintivo não a partir das características essenciais da humanidade como tal, mas a partir das relações institucionalizadas entre os indivíduos e seus governos e outros agentes políticos. A concepção política de direitos humanos está mais bem equipada para captar esse aspecto da prática dos direitos humanos do que a concepção tradicional.

Em terceiro lugar, não é necessário assumir que os direitos humanos são essencialmente ligados a algumas características da humanidade para compreender a ideia (importante) de que os direitos humanos são universais. Os direitos humanos não são eternos (por exemplo, Beitz, 2009), mas isso não significa que eles não sejam universais. Como Raz argumentou de forma convincente, podemos fazer justiça tanto à ideia de que aquilo que os direitos humanos são está enraizado na prática contemporânea quanto à ideia de que os direitos humanos são universais caso sejam entendidos como 
"sincronicamente universais", ou seja, como direitos que todas as pessoas vivas hoje têm (Raz, 2010, p. 41). Esta descrição da universalidade dos direitos humanos é compatível com estes mudando ao longo do tempo.

Finalmente, e crucialmente para o argumento que apresento neste artigo, o re-lançamento do projeto de direitos humanos em 1948 oferece recursos justificativos indisponíveis na tradição dos direitos naturais. Isso me leva de volta à questão sobre o que justifica os direitos humanos. O que tenho em mente é explicado de forma melhor através de uma analogia com a ideia de Rawls sobre uma concepção política de justiça. Como é bem sabido, Rawls propôs contornar as controvérsias sobre a moralidade da justiça desenvolvendo uma concepção de justiça com base em valores políticos fundamentais incorporados na democracia. O projeto político distinto - e muito bem sucedido - que relançou os direitos humanos, similarmente, oferece um modo de contornar a questão altamente contestada sobre os aspectos essenciais que caracterizam os seres humanos em vez de oferecer uma descrição baseada nos aspectos mais amplamente reconhecidos da prática contemporânea de direitos humanos.

Estou ciente de que esta breve discussão toca muito sutilmente no debate sobre as concepções de direitos humanos. Mas, mesmo se as considerações que listei realmente dão apoio a uma concepção política de direitos humanos, ainda há a questão sobre em que ela consiste exatamente. Já mencionei que para Rawls a principal característica da prática contemporânea de direitos humanos é aquela em que os agentes políticos internacionais estão autorizados a intervir e usar a coerção para fazer valer tais direitos (Rawls, 1999). Como James Nickel (2007, p. 98) argumentou, no entanto, a interpretação "ultraminimalista" de Rawls sobre os direitos humanos negligencia a multiplicidade de papeis que os direitos humanos desempenham. Embora seja verdade que alguns direitos humanos servem como base para a intervenção internacional, esta não é de nenhuma forma uma função central dos direitos humanos. Outras funções importantes são estabelecer padrões e aspirações para o debate político internacional, para a política interna, e para os tratados internacionais e as organizações internacionais e globais ${ }^{6}$. 
O tratamento detalhista de Nickel identifica os seguintes principais aspectos da prática contemporânea de direitos humanos (2007, p. 9 ss). Os direitos humanos são direitos; eles estão associados com os titulares dos direitos e os destinatários, e exigem ou proíbem ações. Eles são normas universais de alta prioridade. Seu escopo é internacional. Ou seja, eles "não são dependentes, para sua existência ou reconhecimento, de uma promulgação por governos particulares" (2007, p. 10). Além disso, eles definem "padrões internacionais para avaliação e crítica" (2007, p. 10), ou seja, para a razão pública global. Finalmente, eles aplicam-se principalmente às instituições e agentes políticos. Apesar de não especificarem um modelo para a ordem global, eles definem padrões mínimos de conduta governamental decente ${ }^{7}$.

Contra esse pano de fundo, parece-me que a melhor maneira de interpretar os direitos humanos é que eles são direitos individuais associados à legitimidade política em um mundo globalizado. Nesta concepção, a legitimidade política, e não a humanidade, é o conceito central que explica o que os direitos humanos são ${ }^{8}$. A seguir, suporei que os direitos humanos definem um domínio de igualdade em um mundo político globalizado ao estabelecer limites nos procedimentos de tomada de decisão e nas ações dos governos nacionais e ao vincular os padrões para as relações internacionais e as instituições globais.

\section{Direitos Humanos e Legitimidade Cosmopolita}

Quão exatamente deveria ser entendida a relação entre os direitos humanos e a legitimidade política? Para responder esta pergunta, preciso primeiro dizer um pouco mais sobre a legitimidade política.

Embora isso esteja mudando atualmente, por um longo tempo a suposição padrão foi que apenas as instituições políticas dos Estados-nação e as decisões tomadas dentro deles dão origem a um problema de legitimidade. O nacionalismo político, como quero chamar este ponto de vista, geralmente é defendido com o argumento de que há algo de especial sobre a coerção posta em ação pelo Estado-nação ou sobre a autoridade política 
incorporada no Estado-nação. Esse ponto de vista se choca com o entendimento cosmopolita da legitimidade, segundo o qual as comunidades nacionais não são a fonte exclusiva de legitimidade política na esfera global. Em uma visão cosmopolita política, os padrões internacionais ou globais são pelo menos uma fonte de legitimidade nacional, internacional e, possivelmente, global. Esta é uma fraca caracterização. O cosmopolitismo político, assim definido, é compatível com um sistema em que os Estados-nação e seus governos continuam sendo os principais agentes políticos, desde que haja alguma atribuição de autoridade política legítima às convenções internacionais. Mas a definição não exclui a ideia muito mais exigente do que os Estados-nação e os governos nacionais serão substituídos - pelo menos em certas áreas políticas - por instituições globais ${ }^{9}$.

Eu acredito que o nacionalismo político é difícil de defender hoje - por razões tanto empíricas quanto normativas. $\mathrm{O}$ surgimento da prática contemporânea de direitos humanos é um fator entre outros que desafia a imagem nacionalista política. Mesmo que seja verdade que esta prática deva sua existência a convenções e tratados entre Estados particulares, os direitos humanos hoje, como mencionado acima, estão em vigor independentemente desses Estados (bem como dos Estados que não estavam inicialmente envolvidos). De modo mais geral, muitos comentaram sobre como as instituições internacionais e globais começaram a assumir papeis tradicionalmente limitados aos Estados e sobre o surgimento de formas de governo no domínio global que já não são redutíveis ao governo liderado pelo Estado. Joshua Cohen e Charles Sabel, por exemplo, argumentam que:

[em] uma extensão substancial e crescente [...] a regulamentação que afeta diretamente a liberdade de ação dos indivíduos, empresas e Estados-nação (e a elaboração de normas para regular esta regulamentação) está ocorrendo [...] em configurações globais criadas pelas nações do mundo, mas não está mais sob o controle efetivo delas. (2006, p. 765)

Como argumentam Eric Cavallero (2010) em respeito ao regime internacional de direitos de propriedade e Andreas 
Follesdal (2011) em respeito às instituições globais como a Organização Mundial do Comércio, o poder coercitivo dessas instituições se relaciona com o fato de que a saída não é mais uma opção viável para os Estados individuais, o que sugere que estas instituições têm uma força regulatória na vida das pessoas além do que pode ser controlado por seus Estados ${ }^{10}$.

Estes desenvolvimentos têm implicações normativas. Se é verdade que as instituições internacionais e globais fazem normas que se aplicam aos agentes individuais, corporativos e políticos, surge a questão sobre o que distingue tal regulamentação do mero exercício de poder ou de uma afirmação de facto, porém injustificada, de autoridade. Se é verdade, como eu creio que é, que a regulamentação internacional e global não mais é totalmente controlada pelos Estados-nação, então uma concepção nacionalista política de legitimidade está incompleta e é necessário algum tipo de cosmopolitismo político para enfrentar os desafios normativos associados com as instituições internacionais e globais.

Como devemos pensar sobre a legitimidade dessas instituições? A resposta depende da concepção de legitimidade que for invocada. Será útil distinguir duas abordagens gerais ${ }^{11}$. Um ponto de vista influente na literatura atual tem sua origem em John Locke (1980). O que distingue o ponto de vista de Locke é que a fonte normativa da autoridade legítima é uma ideia substancial de ordem social que existe independentemente do estado civil. De acordo com este ponto de vista, se um regime político real - ou qualquer agente que afirme uma autoridade de facto - é legítimo depende se ele respeita as restrições normativas relevantes. Quando uma autoridade política ultrapassa essas restrições, ela deixa de ser legítima e, portanto, os cidadãos já não são obrigados a obedecer aos seus comandos. Como tal, a concepção lockeana de legitimidade é negativa: ela oferece uma descrição sobre quando a autoridade efetiva cessa de ser legítima ${ }^{12}$. A literatura contemporânea desenvolveu essa abordagem lockeana de muitas maneiras, mas suas características distintivas são frequentemente vistas: a legitimidade apoia aquilo que justifica a autoridade política, e o direito de governar depende de respeitar critérios normativos substantivos (por exemplo, Raz, 1986). 
Uma consequência dessa abordagem é que aqueles que tomam a justificação da autoridade como sendo o problema normativo fundamental tendem a minimizar o problema da coerção. Neste ponto de vista, a autoridade política legitimamente recorre à coerção para impor os direitos que ela deve proteger ${ }^{13}$. Em uma abordagem alternativa à legitimidade política, no entanto, a coerção é vista não apenas como um meio para impor uma ordem social particular, mas como constitutiva de direitos e, portanto, da autoridade política. A implicação desta alternativa é que os direitos não são instrumentos nãoproblemáticos para garantir uma ordem social ideal, mas eles mesmos são coercitivos e necessitados de uma justificação particular.

Nesta abordagem alternativa, kantiana, a legitimidade política é vista como relacionada com a justificação de coerção $^{14}$. O significado de coerção, na filosofia política de Kant, deriva de seu conceito relacional de direitos. De acordo com Kant, os direitos moldam as relações externas entre os indivíduos, e não a realização dos interesses de um indivíduo isolado. Kant, na obra Metafísica dos Costumes, motiva esta forma de pensar sobre os direitos da seguinte maneira. Ele reconhece a liberdade como o único direito natural ("inato"), onde a liberdade é definida como não ser restringido em suas escolhas pelas escolhas dos outros. Para um indivíduo isoladamente, não há, portanto, nenhuma ameaça à sua liberdade de escolha. Em um contexto social, no entanto, as escolhas que as pessoas querem fazer podem colidir entre si. O problema que surge no contexto social no estado de natureza é que cada um pode querer apresentar certas reivindicações para que os outros respeitem sua liberdade, mas não há uma autoridade política que possa julgar entre reivindicações conflitantes. Os direitos são necessários para preservar a simetria na liberdade individual. Mas eles também são constitutivamente coercitivos; restringem a liberdade de alguém conquistar seus próprios objetivos. Qualquer direito de uma pessoa - independentemente de saber se ele é respeitado ou foi violado - implica em uma restrição para os outros (cf. Kant, 6:231 ss; Ripstein, 2004, e 2009, p. 8; Flikschuh, 2008, p. 389 ss). A ideia-chave que desejo usar para o meu argumento é que a criação de um sistema de direitos e, com isso, de uma autoridade política, tanto é necessária para 
assegurar a liberdade quanto é constitutivamente coercitiva. Isso, na abordagem kantiana, é o problema da legitimidade que um Estado civil enfrenta.

Kant e Locke vinculam a legitimidade da autoridade política ao contrato social. Mas as duas abordagens, obviamente, derivam de diferentes interpretações do papel do contrato social. A fonte da autoridade política legítima para Locke encontra-se em certos direitos naturais. Consequentemente, o apreço a uma ideia substantiva e independente de como o povo deve ser governado é o que distingue uma autoridade política legítima de uma que seja meramente de facto. O contrato social é um veículo para garantir essa ideia no estado civil. Para Kant, em contraste, a justificação de uma ordem política não é redutível à justificação moral. Na visão de Kant, o contrato social é um experimento de pensamento hipotético, destinado a captar uma ideia da razão pública, com o seguinte critério: Cada lei deve ser tal que todas as pessoas pudessem consentir com ela. (Por razão pública entendo a razão de todos, ao invés de uma ideia substantiva.) $\mathrm{O}$ foco não está, portanto, sobre o que pode ser justificado, segundo Locke, mas sobre como a justificação deve ocorrer. Como tal, o contrato social na filosofia política de Kant capta uma ideia processual (Korsgaard, 1997; Pallikkathayil, 2010).

Voltando à questão principal deste artigo, o que se segue a partir de duas abordagens para o modo de teorizar o elo entre direitos humanos e legitimidade? Se considerarmos a abordagem lockeana, os direitos humanos são instrumentos para garantir um conjunto básico de direitos morais na esfera política global direitos morais que limitam as afirmações de autoridade que qualquer agente político pode fazer. Nota-se que esta abordagem é compatível tanto com uma concepção tradicional quanto com uma concepção mista raziana dos direitos humanos. A abordagem lockeana sugere que os direitos humanos são padrões mínimos que definem como o povo deve ser governado.

Esta abordagem enfatiza o que chamei de problema dos padrões: Como pode um padrão de direitos humanos ser comparado com outros direitos e outras considerações que aparecem nas concepções de legitimidade nacional e internacional ou global? Em concepções de legitimidade política interna, o problema toma a forma de como os direitos humanos 
podem impor restrições aos governos nacionais. Considere a recente proposta de referendo na Suíça para proibir a construção de minaretes como um exemplo. Uma maioria raramente elevada da população aprovou a proibição. Mas permanece a pergunta se esta decisão é ilegítima por violar os direitos humanos relacionados à liberdade religiosa. $\mathrm{O}$ primeiro problema da legitimidade, assim, assume a forma de como equilibrar as duas fontes de legitimidade: os direitos humanos e a tomada democrática de decisão. No contexto internacional e global, este primeiro problema de legitimidade política toma a forma de explicitar as restrições que um padrão de direitos humanos pode impor às relações internacionais e às instituições globais. Um exemplo para o contexto global é a legitimidade das intervenções humanitárias, que diz respeito à questão de como a proteção dos direitos humanos deve ser equilibrada com, digamos, a autonomia do Estado.

Este primeiro problema de legitimidade é importante e muito tem sido escrito sobre ele. No entanto, há um segundo problema de legitimidade que afeta a relação entre legitimidade e direitos humanos, e este problema surge a partir da necessidade de justificar o próprio padrão de direitos humanos. Allen Buchanan descreve este problema assim: "Quanto mais seriamente o sistema legal internacional proteger os direitos humanos e mais poder efetivo esse compromisso tiver, mais problemática tornar-se-á a falta de uma justificação pública crível para as normas de direitos humanos" (2008, p. 41). Esse segundo problema é, de certa maneira, mais fundamental que o primeiro, porque se este problema não for resolvido, também não será plausível exigir que as instituições e os agentes políticos nacionais, internacionais e globais devam aplicar e satisfazer um padrão de direitos humanos como parte de um requisito de legitimidade; a ilegitimidade pode aumentar no processo.

Vasuki Nesiah (2009) tem uma excelente ilustração do significado deste segundo problema de legitimidade. Sua análise da recente prática de direitos humanos em relação a situações pós-conflito revela como o quadro de guerra e violência em massa moldou significativamente o conteúdo dos direitos humanos e a ordem de prioridade entre os direitos humanos em particular os direitos associados às intervenções 
humanitárias como a segurança alimentar. Foram despriorizados neste processo os direitos relativos à estabilidade e à segurança $\mathrm{a}$ um mais longo prazo - direitos políticos, em particular resultando às vezes em mais violações até dos direitos priorizados. A conclusão de Nesiah é que o quadro de guerra e violência em massa causou intolerância à justificação do próprio padrão de direitos humanos, com consequências nocivas ${ }^{15}$.

O problema com a abordagem lockeana à legitimidade política é que ela tende a obscurecer este segundo problema. Ela sugere que os direitos humanos, sendo justificados pela razão moral comum, fornecem de forma não-problemática uma proteção contra interferência ilegítima vinda de instituições políticas - nacionais ou não. Como vimos, a abordagem kantiana enfatiza a necessidade de justificar a coerção inerente a qualquer sistema de direitos. Os direitos humanos não são diferentes. A abordagem kantiana como esbocei pode reconhecer ambos os problemas de legitimidade: ela pode explicar por que os direitos humanos fazem parte das restrições que qualquer agente político deve respeitar e também por que há uma necessidade de justificar o padrão dos direitos humanos, já que ele está sendo criado atualmente através da prática dos direitos humanos, com base na razão pública.

A abordagem kantiana como esbocei apoia uma concepção política de direitos humanos. Na obra Metafísica dos Costumes, Kant distingue dois tipos de direitos: "direitos em sentido estrito" e "direitos em sentido lato" (6:232 ss). Estes últimos admitem direitos que expressam e objetivam garantir as obrigações morais. Esta interpretação dos direitos é compatível com a concepção tradicional dos direitos humanos como eu já defini na seção anterior. Interessa-me aqui o outro tipo. Um direito estrito, de acordo com Kant, é "não é mesclado com nada ético" (6:232). Ele não expressa obrigações morais existentes independentemente, que por si só gerariam razões para a ação e, portanto, seriam internamente obrigatórias, mas expressa restrições externas mutuamente coercitivas. Esses direitos são obrigatórios por terem sido criados como direitos, não como uma obrigação moral que eles podem expressar. O foco sobre tais direitos é o que distingue a filosofia política de Kant de sua filosofia moral. 
É certo que, como discutido acima, a filosofia política de Kant conecta a justificação dos direitos estritos à proteção da igual liberdade de todos, onde a liberdade é concebida como o único direito inato (Kant, 6:237). Mas isso não nos compromete com uma concepção moralizada dos direitos humanos no espírito da concepção tradicional. Muito pelo contrário. Kant é muito explícito ao dizer que, embora algum sistema de restrições exteriores seja necessário para proteger a liberdade, não existe razão para esperar que haja um sistema exclusivo que seja apropriado para o propósito.

Se seguirmos a abordagem kantiana nesta forma, isso ajudará a compreender a concepção política de direitos humanos como caracterizei na seção anterior. A ancoragem na liberdade tem que ser flexibilizada e substituída pela afirmação de que os direitos humanos são direitos que são criados para a proteção da igualdade no mundo político globalizado ${ }^{16}$. O que é mais importante para os propósitos deste artigo, ela dá sentido à abordagem justificativa característica da concepção política de direitos humanos. Na visão kantiana conforme esbocei, a justificação não depende de direitos morais que as pessoas têm como sua humanidade, mas sim daquilo que os membros da comunidade política global podem justificar uns aos outros como uma restrição mínima para a autoridade política legítima no domínio global ${ }^{17}$.

Um último ponto: a concepção política de direitos humanos que é compatível com a abordagem kantiana conforme esbocei é curiosamente diferente da versão intervencionista de concepção política. Mesmo entre aqueles que em outros contextos são considerados kantianos, há uma tendência em reduzir a prática dos direitos humanos a algo que funcione como um instrumento global para proteger direitos individuais inalienáveis da interferência do Estado (por exemplo, Rawls, 1999). Temos agora uma melhor compreensão sobre por que esta abordagem é tão estreita: ela não só oferece uma interpretação demasiado anêmica da prática contemporânea de direitos humanos, ela também é baseada em uma abordagem à conexão entre direitos humanos e legitimidade política que obscurece um importante problema de legitimidade. 


\section{Legitimidade e o Direito à Participação Política}

Penso que a grande vantagem do discurso kantiano é que ele pode pôr em foco o segundo problema de legitimidade. Agora quero mostrar como podemos usar essa abordagem para apoiar a afirmação de que o direito à participação política é um direito humano básico que não pode ser excluído nem mesmo das listas minimalistas.

Tanto a Declaração Universal dos Direitos Humanos (1948) quanto o Pacto Internacional sobre Direitos Civis e Políticos (1966) reconhecem o direito à participação política.

O artigo 21 da Declaração Universal dos Direitos Humanos afirma:

(1) Toda pessoa tem o direito de tomar parte no governo de seu país, diretamente ou por intermédio de representantes livremente escolhidos. (2) Toda pessoa tem igual direito de acesso ao serviço público do seu país. (3) A vontade do povo será a base da autoridade do governo; esta vontade será expressa em eleições periódicas e legítimas, por sufrágio universal, por voto secreto ou processo equivalente que assegure a liberdade de voto.

O Pacto Internacional sobre Direitos Civis e Políticos não só aceitou tal afirmação, como também é mais exigente. Seu artigo 25 afirma que:

Todo cidadão terá o direito e a possibilidade, sem qualquer das formas de discriminação mencionadas no artigo $2^{\circ}$ e sem restrições infundadas: a) de participar da condução dos assuntos públicos, diretamente ou por meio de representantes livremente escolhidos; b) de votar e de ser eleito em eleições periódicas, autênticas, realizadas por sufrágio universal e igualitário e por voto secreto, que garantam a manifestação da vontade dos eleitores; c) de ter acesso, em condições gerais de igualdade, às funções públicas de seu país.

Embora o direito à participação política seja, portanto, parte desses acordos originais, seu status como um direito humano tem sido objeto de muitas controvérsias, tanto no direito internacional quanto na filosofia política ${ }^{18}$. 
Muitos desses debates se concentram na questão de saber se deveria haver ou não um direito à democracia ${ }^{19}$. Antes que eu possa desenvolver meu argumento em favor do direito à participação política, é importante notar que esse direito não precisa implicar um direito à democracia. Aqui eu sigo Henry Steiner (1988), que argumenta que a participação democrática em plenitude é incentivada como um ideal programático, mas não é exigida pelas convenções de direitos humanos. O motivo é o seguinte. $\mathrm{O}$ direito à participação política tem duas partes: uma "cláusula de eleição" e uma cláusula de "participação" (Steiner, 1988, p. 86). A cláusula de participação é demasiado vaga para exigir qualquer sistema político particular e seria satisfeita pelo direito de participar nos processos políticos deliberativos. A cláusula de eleição é mais específica, mas, também, pode ser satisfeita por sistemas políticos diferentes do autogoverno democrático tal como é modelado, por exemplo, nas democracias ocidentais modernas. Ambas as cláusulas podem, assim, ser interpretadas em maneiras que não impliquem um ideal democrático de igualdade política. $\mathrm{O}$ direito à participação política, entendido desta forma, não pressupõe instituições democráticas nem exige que estas sejam impostas quando estão ausentes.

Embora interpretações mais exigentes do direito à participação política não sejam necessárias, elas não estão excluídas, é claro. Uma indicação disso é a forma como tanto a Declaração Universal e o Pacto Internacional permitem alguma margem de manobra para direitos democraticamente determinados em relação aos direitos humanos incluídos na lista. É claro que muitas sociedades democráticas institucionalizaram amplos direitos à participação política, com consequências para a relação entre a razão pública e a participação política. Em tais sociedades, um processo decisório democrático apropriadamente restrito é visto como necessário para a legitimidade política. Algumas convenções regionais de direitos humanos refletem esse movimento em direção à democracia. A Convenção Europeia (1950), apesar de não mencionar o direito à participação, pressupõe a democracia (cf. artigo 11; Steiner, 2008, p. 471). A Convenção Americana (1969) inclui tanto o direito à participação política segundo a caracterização da 
Convenção Internacional (artigo 23; Steiner, 2008, p. 473) quanto o direito à democracia (artigo 29; Steiner, 2008, p. 473).

Em muitos países, as instituições políticas que se assemelham às de uma democracia estão atualmente ausentes em grande parte. Nesses países, assim, no momento não há um esforço institucional em direção a um direito à democracia ${ }^{20}$. Uma resposta a esta situação é tratar a participação política democrática mais como um ideal programático do que uma caracterização plausível do que o direito à participação política implica. Se a relação entre o direito à participação e a democracia é entendida dessa forma, o direito à democracia é visto como um ideal que dá ao direito legal à participação política o seu conteúdo e objetivo específicos, por exemplo, através de um conjunto de padrões para a cláusula de participação e a cláusula eleitoral. Uma implicação deste ponto de vista é que a participação política que não seja totalmente democrático é necessariamente deficiente em alguns aspectos. A literatura recente sobre democratização (por exemplo, Carothers, 2002) desafia o paradigma de transição, entretanto, e um ponto de vista alternativo está tomando forma. Com base em pesquisas sobre novas formas de participação política, tanto em democracias ocidentais quanto em países com outros regimes políticos, este paradigma alternativo na pesquisa de democratização centra-se na possibilidade de uma convivência estável de elementos de diferentes tipos de regime democrático e autoritário - e examina a diversidade de canais de participação política para além da política eleitoral democrática tradicional (por exemplo, Norris, 2002) ${ }^{21}$. Esse ponto de vista fornece um forte apoio para uma caracterização mais flexível do direito à participação política que não seja modelado numa democracia plena e que não enfatize a participação nas eleições em detrimento de outras formas de participação política.

Será que o discurso kantiano apoia o direito à participação política, entendido neste sentido fraco? Afinal, como vimos acima, a fonte normativa da legitimidade, para Kant, é o consentimento hipotético. Como tal ideia apoia a participação política? Em resposta, quero argumentar que podemos extrair bastante do tratamento da legitimidade de Kant para apoiar um direito humano à participação política. $\mathrm{O}$ argumento baseia-se na relação entre legitimidade política e 
razão pública conforme desenvolvi na seção anterior. O papel da razão pública marca a diferença fundamental entre os discursos de Kant e de Locke sobre a legitimidade política, principalmente por causa da interpretação processual da relação entre razão pública e legitimidade política que encontramos em Kant. O discurso de Locke sugere que o padrão dos direitos humanos é justificado independentemente do processo político e pode ser invocado para legitimar a autoridade política. No discurso de Kant, em contraste, a justificação de um padrão de direitos humanos não é independente do processo político. A ênfase de Kant sobre a autorização para fazer uso público da razão de alguém para destacar déficits de legitimidade (8:304) deixa isso claro. O pensamento é que sem algum direito de participar no processo deliberativo que constitui a razão pública, não há nenhuma justificação e, portanto, nenhuma legitimidade política.

Entendida dessa maneira, a abordagem kantiana apoia o direito à participação política no sentido fraco. Em verdade, a razão pública pode ser invocada para apoiar uma série de direitos. Mas quais outros direitos que ela pode plausivelmente apoiar não é importante para o meu argumento aqui. Não estou tentando responder à questão geral sobre que direitos humanos existem; só estou tentando argumentar que o direito à participação política tem seu lugar mesmo nas listas minimalistas, independente do que esteja nelas. E o que podemos extrair do discurso kantiano é que o direito à participação política na sua interpretação fraca, aquela que enfatiza a participação nos processos deliberativos sem se estender a um direito à democracia, é proeminente entre elas.

$O$ passo final do meu argumento diz respeito ao âmbito da exigência da razão pública. Embora a abordagem kantiana aqui esboçada seja bem pouco exigente no que diz respeito ao conteúdo do direito à participação política, ela é potencialmente bastante exigente no que diz respeito ao seu escopo. O pensamento é mais bem articulado em termos da distinção que apresentei anteriormente entre nacionalismo político e cosmopolitismo político. Se os direitos humanos são entendidos como um sistema sincronicamente universal de direitos - os quais são, em um dado momento no tempo, válidos além das fronteiras políticas e, pelo menos até certo ponto, independentemente das atitudes dos governos dos diferentes 
Estados - então a legitimidade exige que sua justificação também transcenda as fronteiras políticas. Isto implica que uma concepção nacionalista política sobre legitimidade política é insuficiente e que a exigência da razão pública deve ser entendida numa forma cosmopolita política.

$\mathrm{O}$ direito à participação política, como é interpretado atualmente, é limitado à participação em questões de governo nacional. Se meu argumento está correto, ele exige que esse direito seja estendido à participação em debates globais sobre criação de regras por meio de instituições internacionais e globais, incluindo debates sobre o próprio padrão de direitos humanos. A participação política em nível nacional - seja na forma de participação no processo deliberativo, representação que Rawls chamou de uma hierarquia de consulta (1999, p. 71 ss), ou de participação democrática - falhará em estabelecer a legitimidade em um mundo globalizado. Para ter uma força de legitimação num contexto de restrições globalmente conectadas, a razão pública deve igualmente ser de alcance global.

Mas como devemos compreender a razão pública global? Felizmente, o sistema existente permite alguma participação no debate global através da participação em fóruns nacionais ou regionais, e essa participação pode muitas vezes ser suficiente. Por exemplo, o protocolo facultativo do Pacto Internacional sobre os Direitos Civis e Políticos, ratificado por 113 dos 165 países que ratificaram o protocolo principal, permite que indivíduos se queixem diretamente ao Comitê de Direitos Humanos que um dos Estados violou seus direitos humanos. $\mathrm{O}$ Tribunal Europeu dos Direitos Humanos também permite reclamações diretas de indivíduos. Ele gerou um grande corpo de jurisprudência em matéria de direitos humanos e seus casos muitas vezes inspiram o debate público (Nickel, 2007). Esses canais podem, assim, ser usados para contribuições ao debate político global a partir de dentro de fóruns nacionais ou regionais.

No entanto, surge um problema caso esses canais sejam insuficientes para criar uma razão pública global. Por exemplo, questões de regulação transnacional, tais como as que surgem com a imigração, proteção ambiental ou comércio, especialmente se elas envolvem formas de governo que não estão no controle de organismos nacionais nem se inclinam ao 
interesse de alguns Estados nacionais em detrimento de outros, podem exigir um debate mais imediatamente globalizado ${ }^{22}$. Um direito de participar nos processos de justificação pública de ações políticas em nível global torna-se, então, necessário para permitir o tipo de razão pública global que a legitimidade política exige. Vice-versa, caso a participação política permaneça confinada à participação em debates nacionais, isso vai criar um déficit de legitimidade nos casos em que a razão pública nacional tiver um alcance insuficiente. Meu argumento implica, portanto, que se os canais existentes forem insuficientes, pelo menos a cláusula de participação do direito à participação política deve ser estendida para aplicar-se aos processos deliberativos além do contexto nacional. Canais adicionais - por exemplo, a criação de novos tribunais que possam tratar de questões globais - devem ser criados para facilitar a participação no debate político global, incluindo debates sobre a justificação dos padrões de direitos humanos ${ }^{23}$.

\section{Bibliografia}

APPLBAUM, A. Legitimacy Without the Duty to Obey, in Philosophy and Public Affairs, $\mathrm{n}^{\mathrm{o}}$ 3, vol. 38, pp. 215-239, 2010.

BAYNES, K. Discourse Ethics and the Political Conception of Human Rights, in Ethics and Global Politics, $\mathrm{n}^{\mathrm{o}}$ 1, vol. 2, 2009.

BEITZ, C. The Idea of Human Rights. Oxford: Oxford University Press, 2009.

BESSON, S. Theorizing the Sources of International Law, in: BESSON, S., TASIOULAS, J. (eds.) The Philosophy of International Law. Oxford: Oxford University Press, pp. 163$185,2010$.

BUCHANAN, A. Human Rights and the Legitimacy of the International Order, in Legal Theory, vol. 14, pp. 39-70, 2008. BUCHANAN, A. Justice, Legitimacy, and Self-Determination. Oxford: Oxford University Press, 2003.

BUCHANAN, A., KEOHANE, R. O. The Legitimacy of Global Governance Institutions, in Ethics and International Affairs, $\mathrm{n}^{\circ}$ 4, vol. 20, pp. 405-437, 2006. 
BYRD, B. S., HRUSCHKA, J. From the State of Nature to the Juridical State of States in Law and Philosophy, vol. 27, pp. 599-641, 2008.

CAROTHERS, T. The End of the Transition Paradigm, in Journal of Democracy, $\mathrm{n}^{\mathrm{o}}$ 1, vol. 13, pp. 5-21, 2002.

CAVALLERO, E. Coercion, Inequality and the International Property Regime, in Journal of Political Philosophy, $\mathrm{n}^{\mathrm{o}}$ 1, vol. 18, pp. 16-31, 2010.

CHRISTIANO, T. An Instrumental Argument for a Human Right to Democracy, in Philosophy and Public Affairs, $\mathrm{n}^{\circ} 2$, vol. 39, pp. 142-176, 2011a.

CHRISTIANO, T. Introduction to Symposium on Ethical Dimensions of International Institutions, in Politics, Philosophy \& Economics, vol. 10, pp. 3-4, 2011 b.

COHEN, Ja., SABEL, C. Global Democracy?, in New York University Journal of International Law and Politics, $\mathrm{n}^{\circ} 4$, vol. 37, pp. 763-797, 2006.

COHEN, Je. Rethinking Human Rights, Democracy, and Sovereignty in the Age of Globalization, in Political Theory, $\mathrm{n}^{\circ}$ 4, vol. 36, pp. 578-606, 2008.

COHEN, Jo. Is There a Right to Democracy? in SYPNOWICH, C. (ed.), The Egalitarian Conscience. Oxford: Oxford University Press, pp. 226-248, 2006.

COHEN, Jo. Minimalism About Human Rights: The Most We Can Hope For?, in The Journal of Political Philosophy, $\mathrm{n}^{\mathrm{o}} 2$, vol. 12, pp. 190-213, 2004.

COUNCIL OF EUROPE, European Convention for the Protection of Human Rights and Fundamental Freedoms, November $4^{\text {th }}, 1950$, as amended by Protocols Nos. 11 and 14, ETS5. Disponível em: www.unhcr.org/refworld/docid/3ae6b3b04.html. Acesso em: 03 dez. 2012.

D'APREMONT, J. The Rise and Fall of Democracy Governance in International Law: A Reply to Susan Marks, in European Journal of International Law, no 2, vol. 22, pp. 549570, 2011.

FLIKSCHUH, K. Kant's Sovereignty Dilemma: A Contemporary Analysis, in Journal of Political Philosophy, $\mathrm{n}^{\circ} 4$, vol. 18, pp. 469-493, 2010. 
FLIKSCHUH, K. Reason, Right, and Revolution: Kant and Locke, in Philosophy and Public Affairs, $\mathrm{n}^{\mathrm{o}} 4$, vol. 36, pp. 375404, 2008.

FOLLESDAL, A. The Distributive Justice of a Global Basic Structure: A Category Mistake?, in Politics, Philosophy \& Economics, vol. 10, pp. 46-65, 2011.

FORST, R. The Justification of Human Rights and the Basic Right to Justification: A Reflexive Approach, in Ethics, $\mathrm{n}^{\mathrm{o}}$ 4, vol. 120, pp. 711-740, 2010.

FOX, G. The Right to Political Participation in International Law, in Yale Journal of International Law, vol. 17, pp. 539-607, 1992.

FRANCK, T. The Emerging Right to Democratic Governance, in American Journal of International Law, $\mathrm{n}^{\mathrm{o}}$ 1, vol. 86, pp. 4691, 1992.

GOULD, C. C. Structuring Global Democracy: Political Communities, Universal Human Rights, and Transnational Representation, in Metaphilosophy, $\mathrm{n}^{\mathrm{o}}$ 1, vol. 40, pp. 24-41, 2009.

GOULD, C. C. Globalizing Democracy and Human Rights. Cambridge: Cambridge University Press, 2004.

GRIFFIN, J. On Human Rights. Oxford: Oxford University Press, 2008.

HELD, D. Law of States, Law of Peoples: Three Models of Sovereignty, Legal Theory, $\mathrm{n}^{\circ}$ 1, vol. 8, pp. 1-44, 2002.

KANT, I. Practical Philosophy (GREGOR, M., ed. e trad.). Cambridge: Cambridge University Press, 1996.

KELLEY, J. Monitoring Democracy. Princeton: Princeton University Press, 2012.

KORSGAARD, C. Taking the Law into Our Own Hands, in REATH, A., HERMAN, B., and KORSGAARD, C. (eds.), Reclaiming the History of Ethics. Cambridge: Cambridge University Press, pp. 297-328, 1997.

LOCKE, J. Second Treatise of Government. (MACPHERSON, C. B., ed.) Indianapolis: Hackett, 1980.

MARKS, S. What Has Become of the Emerging Right to Democratic Governance?, in European Journal of International Law, no 2, vol. 22, pp. 507-524, 2011. 
MILLER, D. Grounding Human Rights, In: Critical Review of International Social and Political Philosophy, $\mathrm{n}^{\mathrm{o}} 4$, vol. 15, pp. 407-427, 2012.

NAGEL, T. The Problem of Global Justice, in Philosophy and Public Affairs, $\mathrm{n}^{\circ}$ 2, vol. 33, pp. 113-147, 2005.

NESIAH, V. The Specter of Violence that Haunts the UDHR: The Turn to Ethics and Expertise, In: MOURIN, J. (ed.), Human Rights Milestones: Challenges and Development in Asia. Bangkok: Asian Forum for Human Rights and Development, pp. 10-29, 2009.

NICKEL, J. Human Rights as Right-Goal Hybrids, manuscrito não-publicado, 2010.

NICKEL, J. Making Sense of Human Rights. Oxford: Blackwell, 2010.

NORRIS, P. The Democratic Phoenix: Reinventing Political Activism. Cambridge: Cambridge University Press, 2002.

ORGANIZATION OF AMERICAN STATES, American Convention on Human Rights, "Pact of San Jose," Costa Rica, November 22 ${ }^{\text {nd }}$, 1969. Disponível em: www.unhcr.org/refworld/docid/3ae6b36510.html. Acesso em: 03 dez. 2012.

PALLIKKATHAYIL, J. Deriving Morality from Politics: Rethinking the Formula of Humanity, in Ethics, $\mathrm{n}^{\mathrm{o}}$ 1, vol. 121, pp. 116-147, 2010.

PITKIN, H. Obligation and Consent I, in American Political Science Review, vol. 59, pp. 991-999, 1965.

RAWLS, J. The Law of Peoples. Cambridge, MA: Harvard University Press, 1999.

RAZ, J. Human Rights in the Emerging World Order, in Transnational Legal Theory, $\mathrm{n}^{\mathrm{o}}$ 1, vol. 1, pp. 31-47, 2010.

RAZ, J. Human Rights Without Foundations, in BESSON, S. and TASIOULAS, J. (eds.), The Philosophy of International Law. Oxford: Oxford University Press, pp. 321-337, 2007.

RAZ, J. The Morality of Freedom. Oxford: Oxford University Press, 1986.

REIDY, D. On the Human Right to Democracy: Searching for Sense Without Stilts, in Journal of Social Philosophy, $\mathrm{n}^{\mathrm{o}} 2$, vol. 43, pp. 177-203, 2012. 
REIDY, D. Political Authority and Human Rights, in MARTIN, R. and REIDY, D. (eds.), Rawls's Law of Peoples: A Realistic Utopia? Oxford: Blackwell, 2006.

RIPSTEIN, A. Force and Freedom. Cambridge, MA: Harvard University Press, 2009.

RIPSTEIN, A. Authority and Coercion, in Philosophy and Public Affairs, $\mathrm{n}^{\mathrm{o}}$ 1, vol. 32, pp. 2-35, 2004.

SIMMONS, A. J. Justification and Legitimacy. Cambridge: Cambridge University Press, 2001.

STEINER, H. Two Sides of the Same Coin? Democracy and International Human Rights, in Israel Law Review, vol. 41, pp. 445-476, 2008.

STEINER, H. Political Participation as a Human Right, in Harvard Human Rights Journal, vol. 1, pp. 77-134, 1988.

TASIOULAS, J. Are Human Rights Essentially Triggers for Intervention? in Philosophy Compass, n. 6, v. 4, pp. 938-950, 2009.

UN GENERAL ASSEMBLY. International Covenant on Civil and Political Rights, United Nations, Treaty Series, December $16^{\text {th }}$, 1966, vol. 999, p. 171. Disponível em: www.unhcr.org/refworld/docid/3ae6b3aa0.html. Acesso em: 03 dez. 2012.

UN GENERAL ASSEMBLY. Universal Declaration of Human Rights, 217 A (III), December 10 ${ }^{\text {th }}$ 1948, Disponível em: www.unhcr.org/refworld/docid/3ae6b3712c.html. Acesso em: 03 dez. 2012.

WHEATLEY, S. A Democratic Rule of International Law, in European Journal of International Law, n. 2, v. 22, pp. 525-548, 2011.

\footnotetext{
Notas

1 Artigo publicado em fevereiro de 2013. Disponivel em: http://www.jesp.org/articles/download.php?id=72. Acesso em: 01 de julho de 2013. O tradutor agradece à autora e aos editores do periódico Journal of Ethics and Social Philosophy (ISSN 1559-3061) pela gentil permissão concedida para traduzir e publicar este texto para fins acadêmicos, além de agradecerao professor Danilo Alves (danilo.alves@gmail.com) pela imensa contribuição na revisão e melhoria desta tradução.
} 
${ }^{2}$ De acordo com Griffin (2008, p. 33), os direitos humanos são "proteções da nossa reputação humana ou [...] nossa condição de pessoas, " de acordo com a qual o nosso status como humanos "centra-se em nosso ser-agente" (2008, p. 32).

${ }^{3}$ De acordo com Rawls (1999, p. 80), o cumprimento dos direitos humanos "é suficiente para excluir a intervenção justificada e forçada por outros povos, por exemplo, por sanções diplomáticas e econômicas, ou em casos graves pela força militar."

${ }^{4}$ Veja também Baynes (2009).

${ }^{5}$ Veja Beitz (2009) e Raz (2007, 2010) sobre as rejeições vigorosas da concepção tradicional pura.

${ }^{6}$ Veja Reidy (2006) para uma defesa da interpretação de Rawls.

${ }^{7}$ Veja também Beitz, que identifica três elementos principais na prática contemporânea de direitos humanos (2009, p. 109): (i) os direitos humanos se aplicam, em primeira instância, às instituições políticas; (ii) eles são "assuntos de importância internacional"; e (iii) eles "protegem interesses individuais urgentes" contra "ameaças padrão" que emergem de uma "vida em um mundo moderno composto de Estados."

${ }^{8}$ Para uma interpretação paralela a estas linhas, veja, entre outros, Joshua Cohen (2006), Jean Cohen (2008) e Gould (2008).

${ }^{9}$ As concepções cosmopolitas de legitimidade são dscutidas, por exemplo, por Rawls (1999), Held (2002), Buchanan (2003, 2008), Buchanan e Keohane (2006) e Besson (2010).

${ }^{10}$ Além do artigo de Follesdal, veja as outras contribuições a um assunto especial de Política, Filosofia e Economia sobre este tópico, editado por Christiano (2011b).

${ }^{11}$ Eu focarei no conceito de autoridade legítima e simplesmente limitarei a questão sobre se a autoridade legítima consiste em obrigações políticas; para uma resposta recente e interessante a essa questão, veja Applbaum (2010).

12 Deveria ser objetado que esse retrato do ponto de vista lockeano negligencia o papel do consenso. Este tem um papel na descrição de como a transmissão de autoridade deve acontecer. Mas dada a ampla interpretação lockeana de consenso, sua principal função nesta descrição é captar o pensamento - ao contrário de Hobbes - de que a autoridade absoluta é necessariamente ilegítima por suspender a lei natural. A fonte da autoridade legítima é assim a lei natural, não o consenso, mas a falta de consenso é uma marca da ilegitimidade, pois indica a suspensão da lei natural. Minha leitura de Locke segue a de Hannah Pitkin (1965, p. 991-99), entre outros. Agradeço a David Miller pelo destaque a esse respeito.

${ }^{13}$ Como Green considera, "ameaças de coerção fornecem uma motivação impositiva e secundária quando a ordem política falha em sua técnica normativa primária de orientação feita pela autoridade" (1988, p. 75).

${ }^{14}$ Eu me beneficiei muito das discussões recentes de Ripstein $(2004,2009) e$ de Flikschuh (2008) sobre a filosofia politica de Kant. 
15 “O fantasma da violência em massa funciona para legitimar e moldar [uma ética e uma prática de direitos humanos voltada à experiência] em detrimento de uma interrogação mais profunda sobre o que é autorizado em nome dos direitos à sombra da guerra" (Nesiah, 2009, p. 10).

${ }^{16}$ Para uma discussão da proposta de Kant sobre a criação de uma autoridade legítima no domínio global, conforme desenvolvida na obra Doutrina do Direito, e as dificuldades que surgem com ela, veja Byrd e Hruschka (2008) e Flikschuh (2010).

${ }_{17}$ Aqui estou tomando emprestadas as expressões de Joshua Cohen (2004).

${ }^{18}$ Para discussões em direito internacional, veja Steiner (1988, 2008), Fox (1992), Franck (1992) e o recente debate no European Journal of International Law com contribuições de Marks (2011), d'Aspremont (2011) e Wheatley (2011).

${ }^{19}$ Entre os filósofos, Joshua Cohen (2006), Griffin (2008, p. 243 ss) e Beitz (2009) argumentam contra o direito à participação politica como um direito à democracia, enquanto Christiano (2011a) argumenta em favor. Veja também Reidy (2012).

${ }^{20}$ Entendo que esse é também a ideia de Charles Beitz (2009). Ele, usando a grande literatura empírica sobre democracias e democratização, argumenta que as circunstâncias empíricas não apoiam um direito à democracia. Mas ele apoia a democracia como um objetivo ambicioso. Além disso, a proposta de James Nickel de interpretar os direitos humanos como "combinações de direito e objetivo" é aqui muito promissora (Nickel, 2010). O pensamento é que os direitos humanos têm tanto um componente de obrigações quanto um componente de aspirações. A prática contemporânea de direitos humanos abrange tanto os direitos (o componente de obrigações) quanto os objetivos (o componente de aspirações) onde os dois podem formar padrões diferentes. Em relação ao direito à participação política, a participação democrática poderia ser interpretada como parte do componente de aspirações, não do componente de obrigações.

${ }^{21}$ Essa literatura também tem uma atitude crítica em relação à ênfase sobre eleições que caracteriza o paradigma de transição e a instituição associada de observação eleitoral. Veja Kelley (2012) para uma análise cuidadosa dos prós e contras da observação eleitoral.

${ }^{22}$ Para uma discussão sobre essa possibilidade e a resposta exigida, veja especialmente Gould (2004, 2009).

${ }^{23}$ Eu me beneficiei muito dos workshops organizados por Rowan Cruft na Universidade de Stirling, e também de seminários no Nuffield College Oxford, na Escola de Economia de Londres, na Universidade de Minho e na Universidade de Warwick. Eu recebi muitos comentários valiosos de, entre outros, João Manuel Cardoso Rosas, Matthew Clayton, Rowan Cruft, Antony Duff, Katrin Flikschuh, Chandran Kukathas, Dean Machin, David Miller, Avia Pasternak, Massimo Renzo, Nicholas Southwood, Kai Spiekermann, Victor Tadros, Leif Wenar e Lea Ypi. Revisores anônimos também me ajudaram muito a melhorar o artigo. 